\title{
DEVELOPMENT OF THE INTEGRATED MODEL OF THE AUTOMOTIVE PRODUCT QUALITY ASSESSMENT
}

\author{
Hadi Amineh \\ Department of Aviation Devices and Measuring \\ N. E. Zhukovsky National Aerospace University "Kharkiv Aviation Institute" \\ 17 Chkalov str., Kharkiv, Ukraine, 61070 \\ hadiamineh@hotmail.com \\ Nataliya Kosach \\ Department of Aviation Devices and Measuring \\ N. E. Zhukovsky National Aerospace University "Kharkiv Aviation Institute" \\ 17 Chkalov str., Kharkiv, Ukraine, 61070 \\ nataliya.kosach@khai.edu
}

\begin{abstract}
Issues on building an integrated model of the automotive product quality assessment are studied herein basing on widely applicable methods and models of the quality assessment. A conceptual model of the automotive product quality system meeting customer requirements has been developed. Typical characteristics of modern industrial production are an increase in the production dynamism that determines the product properties; a continuous increase in the volume of information required for decision-making, an increased role of knowledge and high technologies implementing absolutely new scientific and technical ideas. To solve the problem of increasing the automotive product quality, a conceptual structural and hierarchical model is offered to ensure its quality as a closed system with feedback between the regulatory, manufacturing, and information modules, responsible for formation of the product quality at all stages of its life cycle. The three module model of the system of the industrial product quality assurance is considered to be universal and to give the opportunity to explore processes of any complexity while solving theoretical and practical problems of the quality assessment and prediction for products for various purposes, including automotive.
\end{abstract}

Keywords: model development, automotive product quality, technical control, automotive products, customer requirements, product quality improvement, high-quality products.

\section{Introduction}

International recognition of the country and its credibility depend on the quality of manufactured products. Therefore, all great world manufacturers pay great attention to the product quality and, in particular, to the automotive product quality, decisively affecting formation of consumers' preferences and competitiveness both of multinationals automobile corporations, automakers, and automobile sales centers and service stations. Therefore, the quality management system (QMS) of the automotive products at appropriate companies is believed to be strategically important aspect of their operation, allowing to adapt to rapidly changing requirements of consumers and the external market, to improve their competitiveness. So formation of effective, meeting the current requirements of the product QMS become urgent these days.

Currently Ukrainian product quality often seems to be unsatisfactory for some reasons, in particular, due to the low level of the QMS implementation, directly affecting the product quality.

Therefore, in order to release competitive products, effective management systems and quality control over released products should be developed and implemented at enterprises based on domestic and foreign experience, which may ensure a proper level and determine the level of development of the country's economy in this economic sector in the world market.

As we know, issues of the product quality assessment within technical control of industrial plants are considered to be a top priority in most countries and, in particular, the UK, Germany, USA, and Japan [1-12]. 
Quality management in the stream production like the automotive industry is considered to be complicated because of the following reasons [1]:

- all processes at the automotive company are mandatory, since they are involved into achievement of the main purpose of production to meet customers' requirements (demands);

- in the production process, a product is manufactured which tangibly complete material streams of the main logistics object, for creation of which material support is required;

- material flows always pass through transformation processes, required to meet consumers, from their creation location to the point of final use;

- necessity to control the quality of production operations binding supply (inbound logistics) and distribution (outbound logistics).

It should be noted that solutions in the production are characterized by strategic nature, since they are associated with significant investments and cannot be quickly reversed. Therefore taken decisions in production largely predetermine restrictions on decisions regarding supply and distribution, as well as the entire supply chain.

All production operations are defined as a transformational process that uses resources: buildings, machinery and equipment, financial resources, materials, human and information resources, knowledge, and other, and with certain technologies, converts them into products. During transformation, product qualities (properties) that meet consumers' expectations are achieved.

\section{Materials and Methods}

To assess the product quality, two approaches are used, namely the quality assessment according to standards applied at an automobile enterprise, and qualimetry methods. The first approach is based on experience, certain historical traditions in the industry, reflected in the relevant government and industry standards for a certain type of product. The second approach is based on modern qualimetry methods for evaluation of the product quality based on the corresponding generalized (integrated) indicator [1].

While designing the product quality, the quality function deployment methodology is accepted as a basis using the concurrent engineering principles, where cross-function commands are used at all stages of the product development. Each stage of the Quality Function Deployment (QFD) process uses control stages or matrix from the initial planning stage to the production end, representing a specific set of requirements for the product [2].

\section{Experimental procedures for development of the automotive product quality assurance system}

Stage 1 - Product planning: development of the quality passport - the customer's documented requirements to the product, its warranty, competitive advantages, taking into account the results of the study of competing cars, as well as the manufacturer's technical capabilities to meet the customers' requirements; the product unified quality indicators (UQI) are formed, etc. Thus the customer's requirements are considered to be crucial.

Stage 2 - Product projecting and designing: product development designing - a creative approach and innovative ideas are required when developing specifications, which are considered the most important to satisfy the consumers' requirements during planning.

Stage 3 - Development of production processes and technological parameters (or target indicators): their indicators are documented, the quality target indicators of the whole system by released products are fixed basing on the selected reference sample or an "ideal" planning model.

Stage 4 - Production process management: indicators, developed for production process control, are used, technical maintenance and operators' trainings are scheduled, decisions on processes of the greatest risks and on defect prevention are made.

For example, the developments of research companies Hui Zhou and YiQiu Human Factors Research Unit allow to plan a comfortable driving basing on the mathematical model of the car dynamic system that can be a very useful tool for the developers involved into the car design at stage 2 of its conceptual design. Also, as a result of the own researches, this company has developed a simple mathematical model to determine the vibration influence on the car and driving quality that is believed to be crucial to its performance characteristics and consumer properties [3]. 
Another very important problem of the automotive industry is to reveal and eliminate defects because "ignoring defects may result in serious consequences for the business organization" [4-8]. It is currently quite difficult to take into consideration complexity, time and cost of surveillance and prediction of the car quality. To meet the high quality and reliability requirements, the car manufacturers put considerable efforts aimed at software development for its verification and validation. Testing with software is an important part of ensuring proper functioning and reliability of all car systems. At the same time, such testing is also considered to be resource-intensive activity, accounting for $50 \%$ of the total costs of the appropriate verification and validation [9], to have a good test strategy with the proper software is essential for any industry.

The algorithm of the product designing meet customers' requirements is given in Fig. 1.

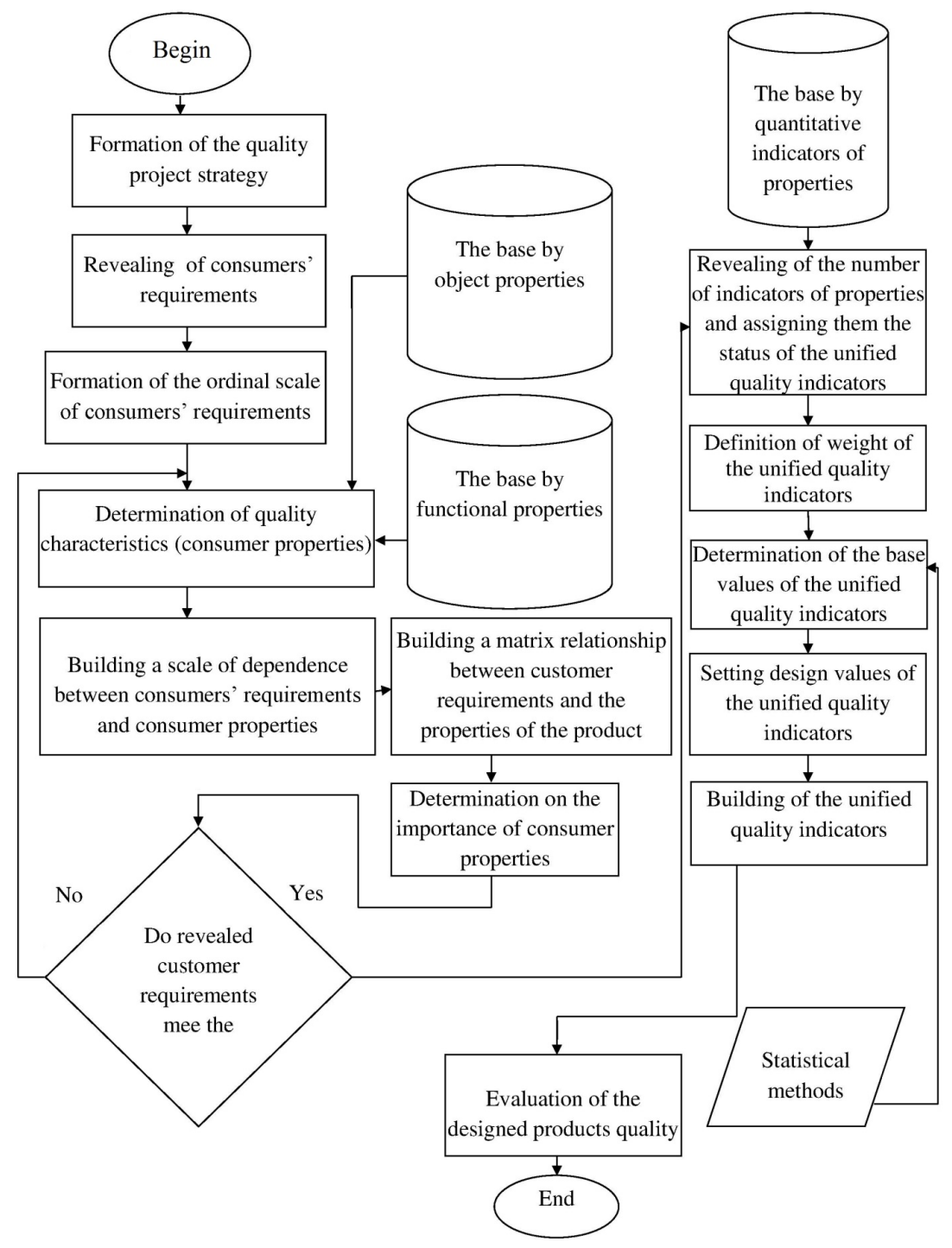

Fig. 1. Algorithm of the product designing meet customers' requirements

In accordance with the algorithm, first, requirements to the test product quality, expressed freely by consumers, are determined. Then, these requirements are transformed into qualitative characteristics (properties). Later most informative quantitative indicators (physical quantities) are selected by each property by assigning them the appropriate status.

In order to increase the product quality, the following principles should be considered [10]:

- focus upon demands of consumers of its market segment, studying of automotive products consumers' preferences via the Internet, including by 24 hour online opinion polls; 
- continuous improvement of the production and activity associated with quality;

- continuous improvement of the competence of the organization's personnel;

- quality assurance at all stages of the product life cycle;

- involvement of all personnel into solving quality problems.

Upon analyzing previous researches in this area, we can point at several aspects of the product quality assurance [11]:

1. Quality control - in some quality control systems, manufactured products are checked and tested by random sampling and all rejected samples are reported.

2. Quality assurance - includes both quality control and high performance, provided mainly by high-quality tools and equipment.

A control chart is used as a statistical control over the production process, which allows to see whether the production process runs according to the plan or the executed work quality does not meet the standards. At the same time, concern for the quality is embodied in the concept of the quality management as a whole - a kind of philosophy of management that puts quality at the center of the company operation being an existence point [12].

An increase in the production process dynamism is considered to be typical features of the modern industrial production determining the product properties; a continuous increase in the volume of information required for decision-making, an increase in the role of knowledge and high technologies implementing absolutely new scientific and technical ideas.

The modern industrial production is characterized by multi-functionality, hierarchy and complexity of the internal structure, resulting in growth of intellectualization of production processes, the need for information and integrative approaches to establish relationships between the individual processes of the quality management systems at different stages of the product life cycle. Under these circumstances, the role of the information support to ensure product quality grows, efficiency of production processes and management increases by ordering and synchronization of information flows between the enterprise's structural and functional elements. Information support of production processes solves issues on document circulation, harmonization and acceleration of cooperation of enterprise's divisions and partners, selection and systematization of enterprise's performance to determine corrective actions aimed at elimination and prevention of inconsistencies, and as a result, leads to increased competitiveness.

Modern requirements for information support at all stages of the product life cycle necessitate to apply intelligent decision support systems (IDSS).

Considering the complexity and multiparametricity of products and processes of the modern industrial production, the intelligent decision support systems should meet the following system requirements:

- openness and adaptability;

- hierarchy and ordering at each level;

- intellectualization (ability to select an appropriate algorithm for operation and information processing according to the change in management tasks, incoming effects and resources available);

- use of modern means of measuring technique, which provide simultaneous execution of measuring and processing of multidimensional information;

- providing analysis of incomplete, inaccurate and contradictory information; ability to analyze indicators of certain characteristics of products and processes (spot estimation) and their aggregates; compression (aggregation) of multi-dimensional information for the transition from a large number of parameters to their generalized estimation; diagnostics, control, recognition of different parameters considering their changes over time and in a multidimensional space of different scales; registration, conversion, and interpretation of large amounts of information;

- ability to solve insufficiently formalized, unstructured problems in incomplete and unclear criteria for decision-making.

\section{Results of the research of the automotive product quality assurance}

To solve the problems of increasing the automotive products quality, the conceptual structural and hierarchical model of quality assurance system is offered as a closed system of feedback 
between the regulatory, production, and information modules, responsible for the product quality at all stages of its life cycle. The scheme of this model is shown in Fig. 2.

The regulatory module includes documents of the quality management system regulating organizational and managerial procedures. Thus, each quality level is linked to the production module and appropriate levels of the information module by feedback through information flows, creating an information three-level model of an industrial enterprise.

The production module is a functional unit of transformation of incoming resources into outputs, regulating processes of formation of product quality at the stage of their manufacture.

The information module consists of three levels of intelligent systems of decision support that form hierarchical relationship of the information systems, namely:

$1^{\text {st }}$ level - collection, analysis, storage, transfer and presentation of the information at all stages of the life cycle;

$2^{\text {nd }}$ level - support of project and management decisions by analytical procedures to obtain forecasts and scenarios of the production processes development, optimization of production parameters with technologies and tools, data analysis;

$3^{\text {rd }}$ level - decision making - the highest level of process control by the enterprise's top management according to the set goals and QMS policy.
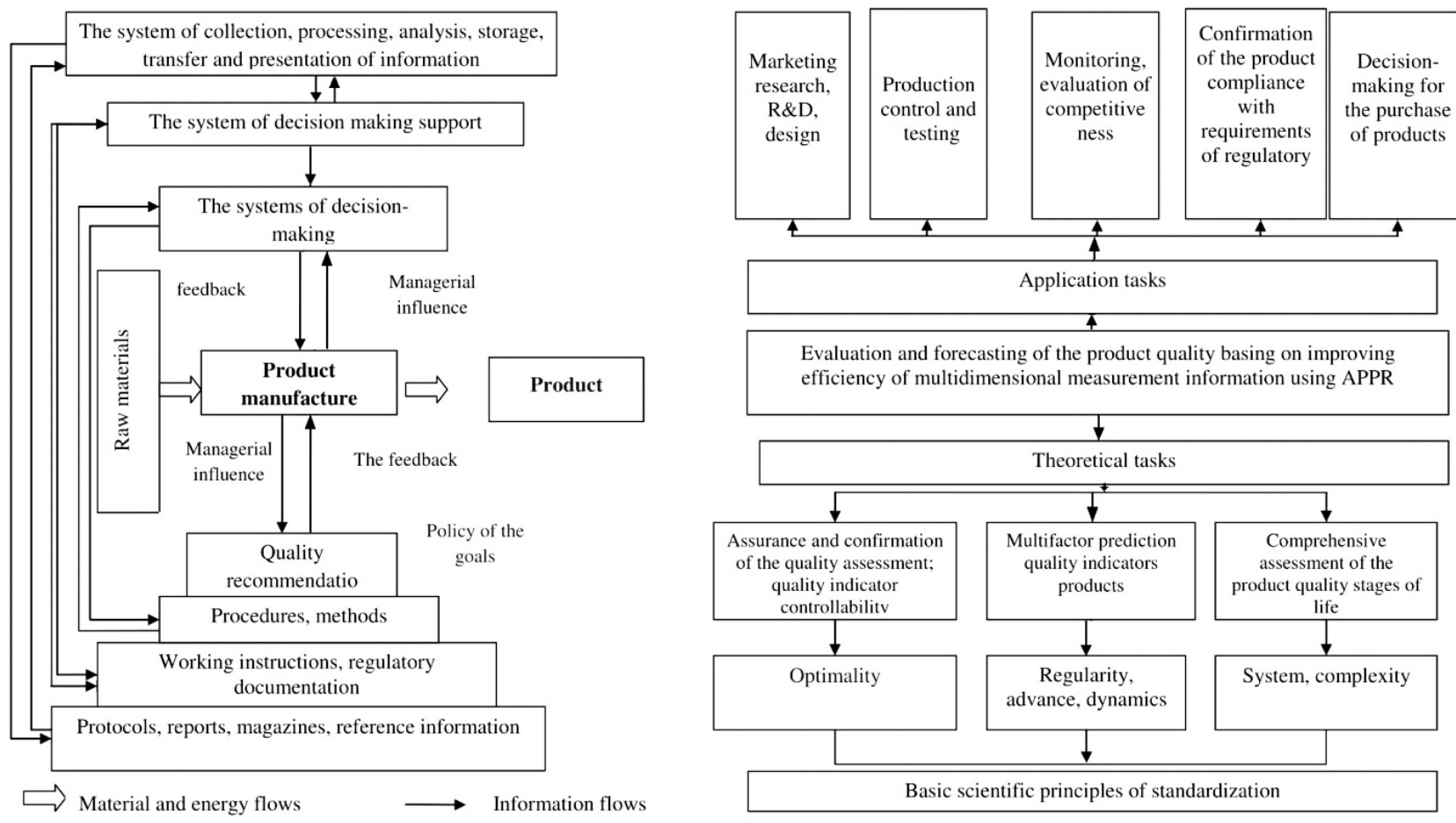

Fig. 2. Scheme of quality assurance for the automotive product

At the same time, the information module provides the organizational and technical system functioning associated with the necessity of operational analysis of large volumes of quantitative and qualitative information in solving unstructured problems that require computer and software tools of modeling, forecasting, and systematization of information on the basis of applied statistical methods, CALS technology, fuzzy logic, neural networks, Data Mining techniques [13].

These technologies and tools make a basis for intelligent decision support systems and are used to assess and predict the product quality, to improve the efficiency of multi-dimensional information processing during preventive and corrective actions in the quality management system.

The three modular model of the industrial product quality assurance system is universal and gives the opportunity to study processes of any complexity in solving theoretical and practical problems of assessment and prediction of the product quality for various purposes, including automotive one. 
Automobile enterprises' operation represents a complex of interrelated factors - people, technique, technology, acting as a single unit with the effective functioning of the technical services. The term "technology" refers to combination of experience, knowledge, skills, materials, machines, tools and equipment, used in production. The developed scheme of interaction between technical, social, and environment of the automobile enterprise is given in Fig. 3.

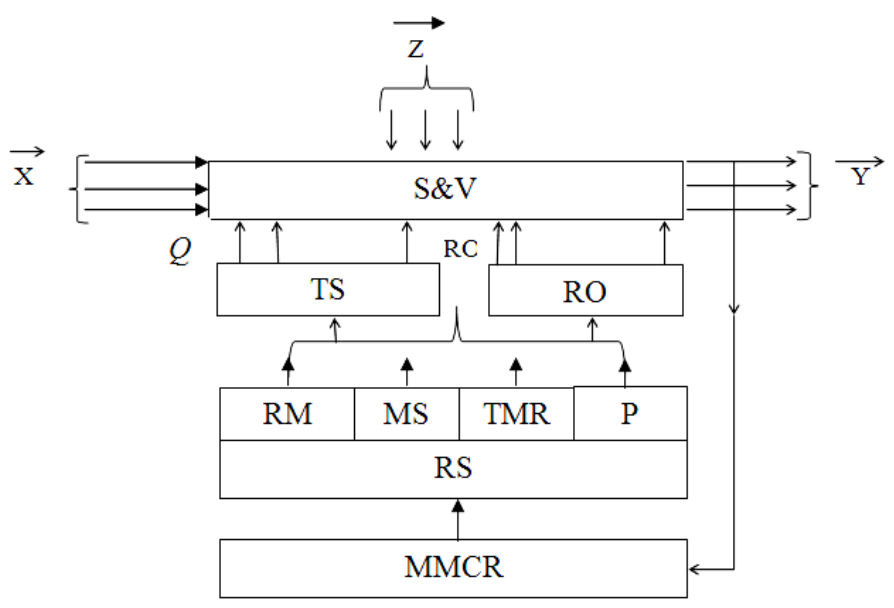

Fig. 3. System of interaction of human-machine-environment of the automobile enterprise: $\mathrm{S} \& \mathrm{~V}$ - system and vehicles (cars) at service centers; $\mathrm{X}$ - factors providing operation (manpower, fuel, oil); Z - factors characterizing the reliability indicators (operating conditions, service personnel qualification, and so on); Q - factors, characterizing the internal state; $\mathrm{Y}$ - technical condition of the equipment and basic characteristics of their reliability indicators;

MMCR - management methods, level of the car reliability; RS - repair system; RM - repairing materials; TMR - technical maintenance and repair; MS - maintenance supply; P - personnel;

$\mathrm{TS}$ - technical support; $\mathrm{RO}$ - repair operations

Physical and natural resources are limited in any production activity. So, they should be used to provide base for long-term development (almost endless). This means ensuring inexhaustible sources in the development process at planning its intensity growth.

While the product quality is planned to be improved, the enterprise should be considered to have sustainable economic development. This is associated with certain expenses for the product quality different for each industry and enterprise depending on their level.

We would like to present the updated production model of economic subjects, adapted to automotive enterprises, associated with modern concepts of the sustainable economic development. It differs from existing [14] by adding new components $(\mathrm{D}, \mathrm{A}, \mathrm{S})$ in the cost price:

$$
\xi=\mathrm{C}+\mathrm{V}+\mathrm{D}+\mathrm{E}+\mathrm{A}+\mathrm{P}+\mathrm{O}+\mathrm{S}
$$

where $\xi$ - indicator of the market price for products or services; $\mathrm{C}$ - cost of material resources, $\mathrm{V}$ - cost of labor, D - value of energy resources, E - cost of waste and emission disposal, A - value of assets, $\mathrm{P}$ - profit, $\mathrm{O}$ - taxes and charges, $\mathrm{S}$ - social protection at the enterprise.

The index of the enterprise's sustainable development, consisting of various economic entities subject to the enterprise's general policy, but with own operational independence, can be determined by the following formula:

$$
\text { Iesd }=\frac{1}{\mathrm{~m}} \Sigma \psi \mathrm{j} \mathrm{KE}
$$

where $\mathrm{j}=1,2, \ldots, \mathrm{m}, \mathrm{m}$ - the number of economic entities in one enterprise; 


$$
\mathrm{K}_{\mathrm{E}}=\frac{1}{\mathrm{n}} \sum \frac{\left(\mathrm{Et}_{\mathrm{i}}-\mathrm{Eb}_{\mathrm{i}}\right)}{\mathrm{Ec}_{\mathrm{i}}},
$$

the average coefficient of growth /progress for each subject; $i=1,2, \ldots n, n-$ the number of indicators of the subject, $\mathrm{Et}_{\mathrm{i}}-$ the current index of the i subject, $\mathrm{Eb}_{\mathrm{i}}-$ the benchmark for the i subject, $E c_{i}-$ the target indicator of the i subject, $\Psi \mathrm{j}$ - coefficients wt (actual model error) for the subjects.

Proceeding from sustainable enterprise's development, and importance of the product quality, we have the following relation

$$
\Sigma \psi \mathrm{j}=\psi 1+\psi 2+\ldots . .+\psi \mathrm{m}=1 .
$$

For the practical model realization, MS Excel 2010 spreadsheets have been developed, with specific values for individual components of the formula (1): $\xi, \mathrm{C}, \mathrm{V}, \mathrm{D}, \mathrm{A}, \mathrm{E}, \mathrm{O}, \mathrm{S}$.

Tables for "ACCO Motors", with filled values for individual input components, are listed below. "ACCO Motors" is an official "Mazda" dealer. The company is involved into sales of new cars, warranty and maintenance of cars, sale of original spare parts, accessories, car care. Table $\mathbf{1}$ shows the calculations.

Table 1

\begin{tabular}{|c|c|c|c|c|c|}
\hline $\mathbf{N}$ & Expenses & $\begin{array}{l}\text { Optimization } \\
\text { direction }\end{array}$ & $\begin{array}{c}\text { Base indicator } \\
\text { Eb }\end{array}$ & $\begin{array}{l}\text { Objective indicator } \\
\text { Ec }\end{array}$ & $\begin{array}{c}\text { Current indicator } \\
\text { Et }\end{array}$ \\
\hline \multicolumn{6}{|c|}{ Economic indicator Ei } \\
\hline 1 & The cost of material resources & decrease & 18000 & 15000 & 16000 \\
\hline 2 & The cost of labor invested & decrease & 14000 & 10000 & 13400 \\
\hline 3 & The cost of fuel and energy resources & decrease & 5000 & 2000 & 4000 \\
\hline \multicolumn{6}{|c|}{ Environmental indicator Ei } \\
\hline 4 & The cost of waste disposal and emissions & decrease & 5000 & 2500 & 4000 \\
\hline 5 & The cost of the assets & decrease & 3000 & 2000 & 2000 \\
\hline \multicolumn{6}{|c|}{ Social indicator $\mathrm{Si}$} \\
\hline 6 & The cost of taxes and fees & decrease & 15000 & 10000 & 10000 \\
\hline 7 & $\begin{array}{l}\text { The cost of expenses for } \\
\text { social protection of the society }\end{array}$ & increase & 6000 & 8000 & 7000 \\
\hline
\end{tabular}

MS Excel spreadsheet for data input to assess "ACCO Motors" contains approximate component values

An algorithm of estimation of changes in stability indicators was obtained basing on MS Excel. It covers two hierarchical levels:

It level - assessment of progress in sustainable development of the enterprise as a whole;

$\mathrm{II}^{\text {nd }}$ level - assessment of progress in sustainable development of individual entities (divisions) of the enterprise.

To evaluate changes in sustainable development of the enterprise as a whole ( $\mathrm{I}^{\text {st }}$ level), the changes in its individual subjects should be evaluated first. Assessment is based on general category expenses - "economic", "environmental" and "social" (shopping area of each subject obtained for certain time period, the category contains n number of indicators to be assessed).

Correction coefficient $\mathrm{K}_{\mathrm{EJ}}$ by each indicator is defined as the difference between the current indicator and its base indicator. Base expenses $\mathrm{Eb}$ may differ from indicators of target expenses Ec. Each type of expense Ec should be indicated desired (expected) target indicator ("decrease" or "increase") regarding its baseline value $(\mathrm{Eb})$.

Depending on the ratio of the planned values for this indicator, the following assessment may imply:

$-\mathrm{E}_{\mathrm{i}}>0$ - positive change in the indicator regarding the base cost;

$-\mathrm{KE}_{\mathrm{i}}=0$ - the indicator amendment regarding the base cost is not taken into account;

$-\mathrm{KE}_{\mathrm{i}}<0$ - negative change in the indicator regarding the base cost; 
Since the assessment of the progress of individual car sales centers and large auto corporations is a process recurrent in time, using the MS VBA capabilities, macro is designed, integrated in the tables of $\mathrm{I}^{\text {st }}$ and $\mathrm{II}^{\text {nd }}$ level of MS Excel.

Through it, a new "Worksheet" created as a copy of the previous estimation is added in a "Workbook" for each object of each next period of estimations.

For each subsequent estimation (Worksheet), indicators of current expenses $\left(\mathrm{Ec}_{\mathrm{i}}\right)$ are to be set as the base costs (Eb) for the next period. In the early period, the estimation team represent new target indicators for expenses $\left(\mathrm{Et}_{\mathrm{i}}\right)$, and at the end, the actual expenses $(\mathrm{Ec})$ for the previous period are to be set; numeric data estimations and graphic data representation in the chart are automatically updated.

Thus, the accumulated data for individual subjects, and for the whole enterprise make it possible to monitor change rates, stability and profit indicators, formed at its divisions and at the enterprise for long prior periods, as well as to predict their behavior in future.

Continuous evolution of changes at the automobile enterprise leads to effective solutions both at the strategic and tactical, and operational levels $[15,16]$.

\section{Discussion of the investigated issue}

The introduction of new models of organization of maintenance and repair, compliance with car manufacturers' policy and customers' requirements creates the need in the information system for processing large amounts of information in a short time.

The practical use of the model at the information level provides a solution to quality assessment problems during development, production control and product testing, evaluation of competitiveness and confirmation of the product compliance with quality requirements, development of the QMS and control systems of metrological reliability. Thus, the model takes into account the need for the design and development of theoretical approaches regarding the provision of guaranteed quality assessment and multivariate prediction of quality indicators, comprehensive assessment of the product quality at all stages of the life cycle, considering the basic scientific principles of standardization - optimality, flexibility, regularity, dynamics, system, and complexity.

The conceptual model of the quality assurance system for automotive products is implemented for structural and functional modeling of the quality management system. The developed model is an as-is model. It reflects the existing structure and interconnections of the quality assurance system at the life-cycle stages, and according to the principles of the structural analysis and hierarchical ordering determines the order of the system research, which begins with its general description (formalization), then detailing (decomposition), acquiring a hierarchical structure with a large number of levels. This makes it possible to improve the system by various criteria by building simulation to-be models and to determine ways of rationalization of the structures of the quality management system processes, and relationships between them [17-20].

The model determines the structure of the material and information flows between functional blocks of the management system considering constraints of available resources and regulatory documentation. The built model of the quality management system can be used for solution of analytical and prognostic problems of project and management decisions during the product development, manufacture, and operation at all stages of the life cycle.

\section{Conclusions}

Production of high quality products provides great advantages and prospects, in particular in reducing production costs, expenses at working with reclamations, defects elimination, and, net income growth, domestic market expansion and entry into the international market. Therefore, until entrepreneurs understand the urgent need to ensure the quality of their products, they will keep losing their potential income and market share.

Namely, the state and enterprises' top-management together with the shareholders should create all necessary conditions to increase the quality and competitiveness of the national products, sustainable economic development, to improve conditions and living standards, and others.

The developed integrated scheme of evaluation of the information support, quality automotive products as a closed loop with feedback between the regulatory, manufacturing, and informa- 
tion modules of the production makes it possible to improve the product quality while reducing economic expenses. The practical use of this model provides the scientific principles of standardization in solving problems of the product quality control using intelligent systems of decision support.

The conceptual scheme of automotive product quality assurance is implemented for structural and functional modeling of the quality management system. Based on the SADT methodology and IDEF0 standards, taking into account the principles of the system, the process approaches, structural analysis, system model is developed that can be used to solve analytical and prognostic problems of project and management decisions in the design, manufacture and operation of automotive products at all stages of their life cycle.

Thus, this research can be used for assessment of the automotive product quality. The author is planning to develop a method of the automotive product quality assessment.

\section{References}

[1] Zhou, H., Qiu, Y. (2015). A simple mathematical model of a vehicle with seat and occupant for studying the effect of vehicle dynamic parameters on ride comfort. 50th UK Conference on Human Responses to Vibration. Available at: https://pdfs.semanticscholar.org/eb75/506ba9c84ca2a2bbf45572d7879da44b2204.pdf

[2] Ebert, C., Jones, C. (2009). Embedded Software: Facts, Figures, and Future. Computer, 42 (4), 42-52. doi:10.1109/mc.2009.118

[3] Jones, E. L. (2001). Integrating testing into the curriculum - arsenic in small doses. ACM SIGCSE Bulletin, 33 (1), 337-341. doi: 10.1145/366413.364617

[4] Broy, M. (2006). Challenges in automotive software engineering. Proceeding of the 28th International Conference on Software Engineering, 33-42. doi: 10.1145/1134285.1134292

[5] Furst, S. (2010). Challenges in the design of automotive software. 2010 Design, Automation \& Test in Europe Conference \& Exhibition, 256-258. doi: 10.1109/date.2010.5457201

[6] Eklund, U., Gustavsson, H. (2013). Architecting automotive product lines: Industrial practice. Science of Computer Programming, 78 (12), 2347-2359. doi: 10.1016/j.scico.2012.06.008

[7] Mellegard, N. (2013). Improving Defect Management in Automotive Software Development. Chalmers University of Technology, 247.

[8] Grady, R. B. (1996). Software failure analysis for high-return process improvement decisions. Hewlett Packard Journal, 47, 15-24.

[9] Yevdokimova, L. I. (2015). Complex assessment of dynamics of an enterprise's operation effectiveness as a tool for the analytical activity activation at an industrial enterprise. Moscow: Academic International Institute, 150.

[10] Zakharov, M. G. (1999). System quality is the enterprise of self-preservation tool in times of crisis. Standards and quality, 2, 33-34.

[11] Zekunov, A. G., Ivanov, V. N., Mishin, V. M., Pazyuk, Yu. V., Vlasova, T. I. (2015). Quality management. Moscow: Yurait Publishing house, 475.

[12] Medunetsky, V. M. (2013). Fundamentals of quality assurance and certification of industrial products. Saint Petersburg: ITMO, 61.

[13] Huang, E. (2010). Quality Products and Methods of their Evaluation in an Industrial Enterprise. Problems of modern science and practice, 10-12 (31), 248-264.

[14] Hadi, A. (2016). The product quality: characteristics, essence, evolution of approaches. Economy. Management. Modern problems and prospects of development, 4, 64-72.

[15] Kosach, N. I., Siroklyn, V. P., Hadi, A. (2016). The quality of the system engineering company Iran Khodro management. All-Ukraine Scientific and Technic Conference of Young Scientists in Metrology, 1-5, 82-96.

[16] Hadi, A., Kosach, N. (2016). Assessment of Consumers' Satisfaction with the Automotive Product Quality. International Journal of Environmental \& Science Education, 11 (16), 8726-8739.

[17] Stroganov, V. I. (2012). Results and prospects of development of electro mobiles and hybrid vehicles. Electronics and electrical transport, 2.

[18] Vitovtova, A. A. (2016). Analysis and evaluation of quality competitiveness. Kuban State University, 12 .

[19] Leonov, O. A., Temasova, G. N. (2015). Economics of quality. Saarbruken, 305.

[20] Leonov, O. A., Temasova, G. N., Vergazova, Y. G. (2015). Quality management. Moscow: Publishing house RGAU - MSHA, 180. 